\title{
Influence of loading ratio on flat slab connections at elevated temperature: A numerical study
}

DOI:

10.1007/s11709-020-0620-9

\section{Document Version}

Accepted author manuscript

Link to publication record in Manchester Research Explorer

\section{Citation for published version (APA):}

Al Hamd, R., Gillie, M., Mohamad, S. A., \& Cunningham, L. (2020). Influence of loading ratio on flat slab connections at elevated temperature: A numerical study. Frontiers of Structural and Civil Engineering, 1. https://doi.org/10.1007/s11709-020-0620-9

\section{Published in:}

Frontiers of Structural and Civil Engineering

\section{Citing this paper}

Please note that where the full-text provided on Manchester Research Explorer is the Author Accepted Manuscript or Proof version this may differ from the final Published version. If citing, it is advised that you check and use the publisher's definitive version.

\section{General rights}

Copyright and moral rights for the publications made accessible in the Research Explorer are retained by the authors and/or other copyright owners and it is a condition of accessing publications that users recognise and abide by the legal requirements associated with these rights.

\section{Takedown policy}

If you believe that this document breaches copyright please refer to the University of Manchester's Takedown Procedures [http://man.ac.uk/04Y6Bo] or contact uml.scholarlycommunications@manchester.ac.uk providing relevant details, so we can investigate your claim.

\section{OPEN ACCESS}



temperature: A numerical study

\author{
3 Rwayda Kh. S. Al-Hamd ${ }^{1,2 *}$, Martin Gillie ${ }^{3}$, Safaa Adnan Mohamad ${ }^{4}$ and Lee S. Cunningham ${ }^{1}$ \\ ${ }^{1}$ School of Mechanical, Aerospace and Civil Engineering, The University of Manchester, Manchester M13 9PL, UK \\ $5{ }^{2}$ Prosthetics and Orthotics Engineering Department College of Engineering, Al-Nahrain University, Baghdad, Iraq \\ ${ }^{3}$ New Model in Technology \& Engineering (NMiTE), Hereford, Herefordshire HR1 2HX \\ $7 \quad{ }^{4}$ Department of Highway and Transportation Engineering, Al-Mustansiriyah University, Baghdad, Iraq \\ 8 "Corresponding author: E-mail address: rwayda.alhamd@ gmail.com:
}

10 Abstract

11 For reinforced concrete members subjected to high temperature, the degree of in-service loading,

12 commonly expressed as the loading ratio, can be highly influential on the structural behaviour. In

13 particular, the loading ratio may be pivotal in relation to the phenomenon of load-induced thermal

14 strain. Despite its potentially pivotal role, to date, the influence of the loading ratio on both material

15 and structural behaviour has not been explored in detail. In practice, real structures experience variation

16 in imposed loading during their service life and it is important to understand the likely response at

17 elevated temperatures across the loading envelope. In this paper, the effect of the loading ratio is

18 numerically investigated at both material and structural level using a validated finite element model.

19 The model incorporates a proposed constitutive model accounting for load-induced thermal strain and

20 this is shown to outperform the existing Eurocode 2 model in terms of accuracy. Using the validated

21 model, the specific case of flats slabs and the associated connections to supporting columns at various

22 loading ratios are explored. For the cases examined, a marked difference in the structural behaviour

23 including displacement direction was captured from low to high loading ratios consistent with

24 experimental observations.

25 Keywords: concrete, finite elements, fire, load-induced thermal strain, punching shear 


\section{1. Introduction}

2 Flat slab structures represent the simplest form of reinforced concrete frame building since the slab is

3 connected directly to the columns without the presence of beams. In view of this, the slab to column

4 connection in a reinforced concrete flat slab is vital to the strength and stiffness of the slab system. Flat

5 slabs are widely used in commercial and residential frame buildings due to the advantages they offer in

6 situations that involve reduced storey heights, flat finishes, rapid construction and the need to place

7 columns at arbitrary locations. However, despite the many advantages of flat slab construction, there is

8 also a risk that the dangerous brittle failure mode known as 'punching shear' will occur if shear stresses

9 at the slab-column connection reach critical levels.

10 Generally, reinforced concrete (RC) structures have a good reputation for fire resistance due to

11 concrete's low thermal conductivity. However, in some cases, this perception is not strictly correct as

12 it ignores the implication of other aspects such as the effect of combined heating and loading conditions

13 on the mechanical properties of concrete at high temperature. At elevated temperatures such as those

14 occurring in fire conditions, $\mathrm{RC}$ structures lose a lot of their compressive resistance and since punching

15 shear strength is influenced by the tensile strength and hence indirectly by the compressive strength,

16 the slab-column connection would be adversely affected.

17 The first set of tests published on slab-column connections in a fire were by Kordina in the 1990s [1,2].

18 In 2004 following a fire-related collapse of a car park building in Gretzenbach, Switzerland [1], further

19 experimental studies were carried out on punching shear in heated slabs by various researchers. The

20 first of these post-2004 studies was by Salem et al. [3], a schematic of the test set-up is shown in Figure

21 1. The main focus of the work by [3] was the effect of the heating application on the tension side of the

22 slab at the column connection. However, this would not normally be the most affected zone in a real-

23 fire, as the fire will rise upward. To develop an understanding of the effect of heating on different sides 
1 of the slab, compression side or tension side, Liao et al. [4] tested 12 slabs with dimensions of 1800

$2 \times 1800 \times 120 \mathrm{~mm}$, half of the test series were at high temperature, the other half were at ambient

3 temperature. It was concluded by [4] that the worst-case scenario occurs when applying the fire to the

4 tension side of the slab. This conclusion is due to several reasons: firstly, spalling occurs more severely

5 on the slabs heated on the tension side due to the cracks that form[4]. Secondly, the slabs heated on the

6 tension side failed after three to five hours while the slabs heated on the compression side failed after

7 eight hours. Finally, the deflection of the slabs heated on the tension side was far more significant than

8 the deflection of the slabs heated on the compression side. However, the performance of the slabs heated

9 on the tension side may be of less significance since this does not replicate the situation of actual slab-

10 column connections in flat slab frame buildings. One important point to note from Liao et al. [4] is that

11 the slabs heated on the compression side showed the same unexpected deflection behaviour noted first

12 by Kordina [1,2]. Subsequent to the aforementioned work, Smith et al. [5-8] investigated slab-column

13 connection behaviour under fire. They used 16 specimens of dimension 1400 x $1400 \mathrm{~mm}$ and depths of

1450,75 and 100mm; five of which were tested at ambient temperature to determine their punching shear

15 resistance. After applying static loading, the slabs were heated, most of the specimens clearly

16 demonstrated that the slab deflections when heated were in the opposite direction to that which had

17 been expected i.e. away from the heating source rather than towards it. A recent study by Al-Hamd et

18 al $[9,10]$ concluded that the phenomenon of load-induced thermal strain (LITS), which is seen in heated

19 concrete, explains the observed behaviour. 


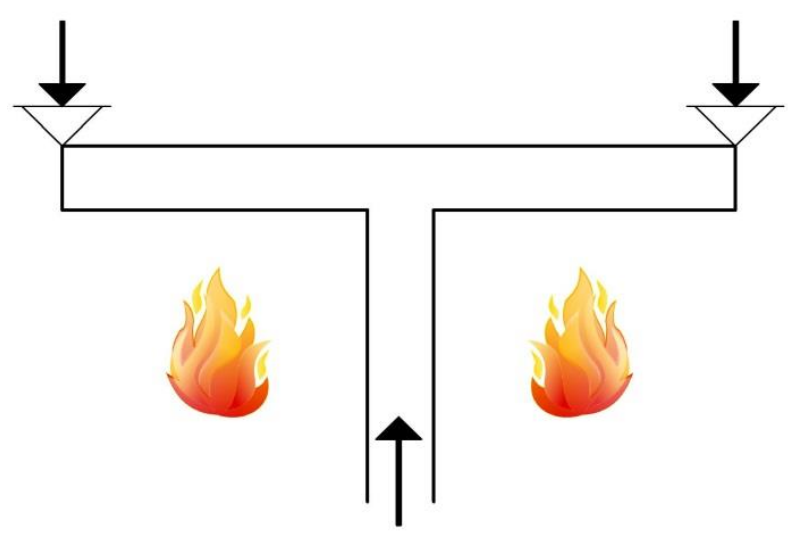

Figure 1 Conceptual drawing for punching shear test set-up and the importance of the heating side

\section{2. Background and motivation}

4 Almost all of the tests conducted to date on flat slabs at high temperature, with the exception of those

5 by Kordina [1,2], consistently applied loads between $60 \%$ and $80 \%$ of the ultimate punching shear

6 capacity of the slab at ambient temperature. The relationship between the applied load and the nominal

7 ultimate load capacity of the slab at ambient temperature is herein referred to as the Loading Ratio

8 (LR). In the aforementioned existing studies, the nominal ultimate load capacity is either taken to be

9 the theoretical value predicted by a design code or based on the experimentally derived value.

10 Observations from the previously conducted tests showed that the higher LRs resulted in a marked

11 change in deflection behaviour compared to that observed in the lower LR cases.

12 In Kordina's original work [1,2] the effect of loading ratio (using three identical circular specimens

13 A, B and C with a diameter of $2500 \mathrm{~mm}$ and thickness of $200 \mathrm{~mm}$ ) was examined. The three specimens

14 were loaded up to 20,40 and $70 \%$ of their ambient temperature ultimate design punching shear

15 resistance (theoretically obtained from the German code DIN 1045:1988 [1,2]) respectively. The

16 heating was applied according to the ISO-834 fire curve [1,2]. Slabs A and B experienced a downwards

17 deflection (towards the heating source) until the slabs failed; however, slab C deflected downwards first 
1 (towards the heating source) and then the deflection direction reversed after 30 minutes of heating, see

2 Figure 2. This unexpected behaviour is noted by Kordina without explanation.

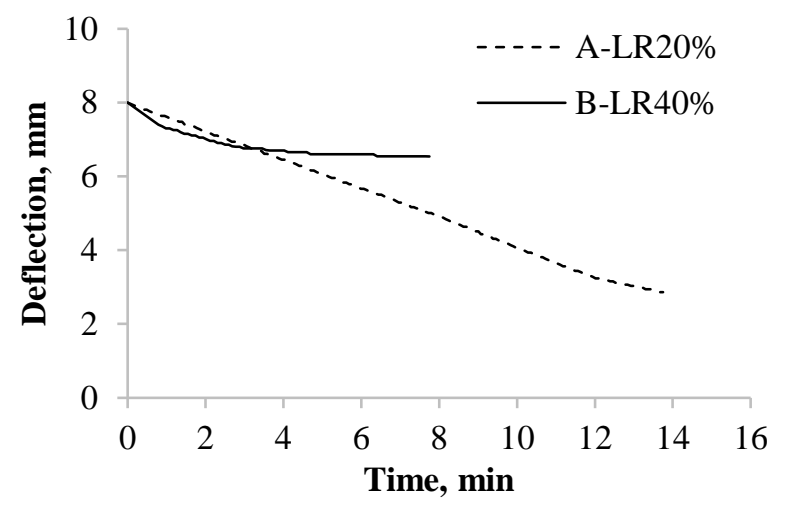

(a)

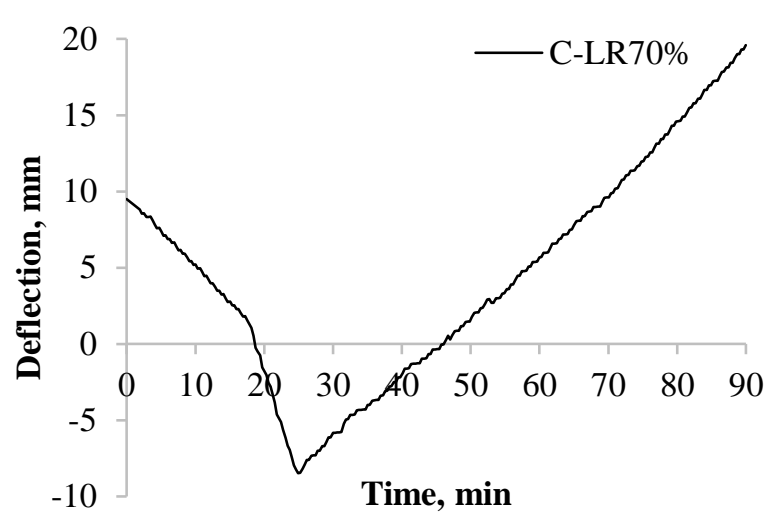

(b)

Figure 2 The load deflection profile for specimens (a) for A, B and (b) for C, based on Kordina [1,2]

5 Similarly, Smith et al. [5-8] implemented an LR of (70-80\%) in all of the tested slabs and the deflection

6 reported was again moving away from the heating source.

7 The level of loading directly affects the concrete behaviour at elevated temperatures and might result

8 in the reversal of the expected deflection response due to the effect of LITS, (defined in detail in the

9 next section), as shown in Figure 3. The effect of the loading ratio on the behaviour of the slab-column

10 connections raises concerns about the design recommendations for heated reinforced concrete

11 members. While some allowance for the effect of LITS is incorporated to some extent in current design

12 codes such as Eurocode 2 (EC2) [11], the models are often limited. The main focus of the present study

13 is to compare the EC2 constitutive model [11] for concrete at elevated temperatures with the novel

14 model developed by Al-Hamd et. al. $[9,10]$ which demonstrated more realistic results in capturing the

15 structural behaviour of the slab-column connection. Although some limited experimental work has been 
1 conducted to examine the effect of loading ratio, no numerical study incorporating accurate capture of

2 LITS has been carried out to date in this particular application. Adopting a numerical approach allows

3 additional insights into the structural behaviour to be gained beyond the practical constraints of physical

4 experiments. In the present paper, the influence of the loading ratio is numerically investigated for the

5 first time at both a material level and in terms of the overall structural behaviour of the connection,

6 utilising a model which captures realistically the LITS effect.

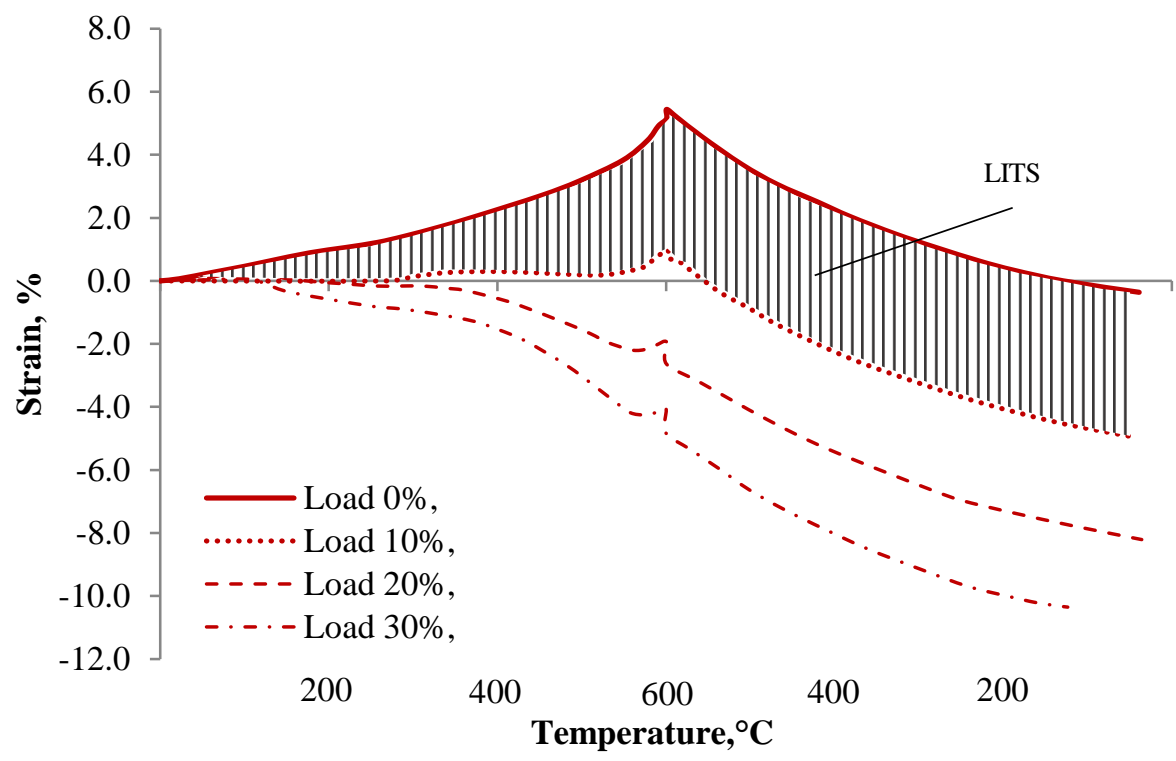

8 Figure 3 Typical LITS behaviour expressed as a function of temperature for different load levels, based on [12]

\section{3. Effect of heating on the strain components of concrete}

10 The combination of fire and mechanical loading results in the generation of different strain components.

11 Therefore, the best way to understand the deformation of concrete at elevated temperatures is by

12 splitting the total strain into its primary components, as shown in the following equation [13]:

$$
\varepsilon_{t o t}=\varepsilon_{\sigma}(\sigma, T)+\varepsilon_{t h}(T)+\varepsilon_{L I T S}(\sigma, T)+\varepsilon_{c r}(\sigma, T, t) \quad \text { Equation } 1
$$

13 Whilst the mechanical strain $\varepsilon_{\sigma}(\sigma, T)$ is a result of the static load, the thermal strain $\varepsilon_{t h}(T)$ is due to

14 the material expansion, the load-induced thermal strain (LITS) $\varepsilon_{L I T S}(\sigma, T)$ is a result of the concrete 
1 shrinking under a high level of applied loading and the creep strain $\varepsilon_{c r}(\sigma, T, t)$ is the strain that develops

2 in the material due to external loading over time[12]. Due to the time scale needed for creep strain to

3 develop, creep strain is often neglected in structural fire calculations[14-16]. This assumption

4 highlights the role of mechanical, thermal and load-induced thermal strain on behaviour of concrete in

5 fire. The effect of heat on concrete with these stain components being developed would increase the

6 loss of the concrete strength, which leads to substantial damage of the reduced cross-section [17-20].

7 Al-Hamd et al. $[9,10]$ put forward an explanation for the unexpected behaviour reported in the 8 experimental tests conducted by [5-8] for the slab-column connections. The main reason for this 9 behaviour is found to be the activation of one of the strain components (LITS) of the heated concrete 10 generated under combined heating and high levels of loading conditions. Al-Hamd et al. also developed 11 a model that can capture the effect of LITS by adding its component separately to the Eurocode 2 (EC2) 12 constitutive concrete model [11]. The model proposed the implementation of the LITS component using 13 the formulation developed by Anderberg and Thelandersson [21,22] in the EC2 concrete model 14 explicitly to capture the effect of LITS. This was in line with the findings of Lange and Jansson [15] 15 that highlighted the weakness in the EC2 concrete model at elevated temperatures. The new model 16 proposed by Al-Hamd et al. that explicitly includes the effect of LITS in the compressive stress-strain 17 relationship of the concrete adopted in this study can be seen in Figure 4 where it is compared to the 18 standard EC2 model at different temperatures. As shown in Figure 4, the solid lines represent the stress19 strain behaviour for concrete without the addition of the LITS component and the dashed lines represent 20 the stress-strain behaviour for concrete with the LITS component added. 


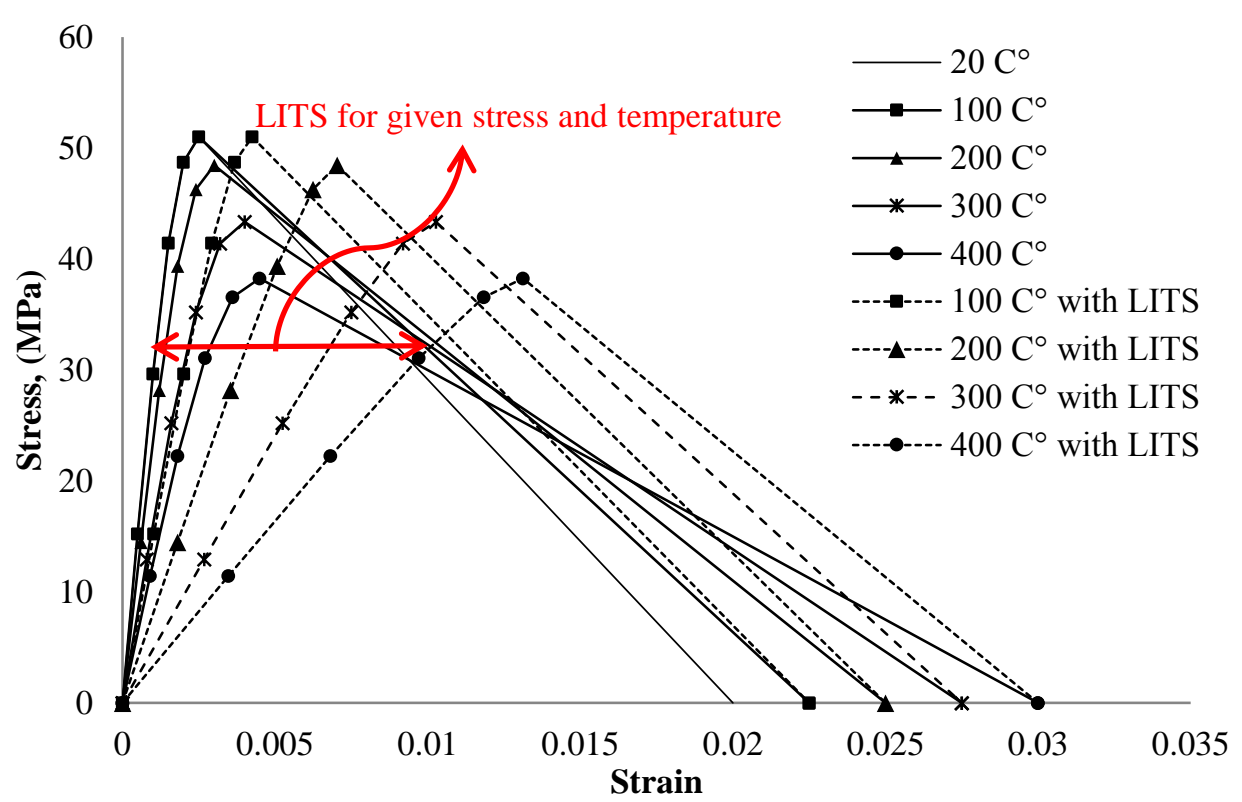

2 Figure 4 Stress-strain behaviour of concrete at various temperatures according to EC2 (solid lines) and EC2 plus loadinduced thermal strain (dashed lines), (based on [9])

\section{4. Modelling approach}

5 There are several approaches for modelling reinforce concrete including the traditional mesh based

6 approach and the relatively new approach of mesh-free methods that can capture directly the

7 discontinuity of cracking in concrete members, [23-27]. In the present work, the traditional mesh

8 based approach is adopted using the general finite element software Abaqus [30]. The concrete

9 constitutive behaviour is modelled using the concrete damage plasticity model available in the Abaqus

10 material library [31\}. This model has been successfully adopted by Jansson and Lange for fire

11 conditions [15]. All models in this study use three-dimensional solid elements (C3D8R) to represent the

12 concrete slab, with truss elements (T3D2) embedded within them to represent the rebar. This approach has

13 a number of advantages such as providing a better representation of the complex three-dimensional stress

14 state that exists near the slab-column interface under punching shear, capturing the shear stresses at the

15 connection in line with[28-30].

16 The modelling approach developed by Al-Hamd et al. $[9,10,30]$ is adapted to produce a numerical

17 model with different LRs at elevated temperatures. In all models, a full-bond between the concrete and 
1 steel rebar is assumed[30]. Whilst this is a simplification of reality, the approach was implemented by

2 [30] for the specific case of punching shear and was shown to have a good agreement with

3 corresponding test results within the level of accuracy of (0.73-8.14\%). Concrete uniaxial stress-strain

4 properties were initially made temperature dependent according to the recommendations in EC2. To

5 simulate high-temperature experiments, first a static load was applied and the effect of heating was

6 introduced using a thermal profile (see Section 5).

\section{5. Model calibration at elevated temperatures}

8 For the calibration of the numerical model, one of the test specimens (originally named as HU75)

9 reported by Smith [8] was simulated. The slab had dimensions of 1400 x 1400 x 75mm and was simply

10 supported along all edges (in a similar configuration to that shown in Figure 1). The concrete damage

11 plasticity model was used to model the concrete where the uniaxial compressive stress-strain

12 relationship was adopted from Eurocode 2 and the mesh size of $12.5 \mathrm{~mm}$ was chosen as the macroscale

13 behaviour of concrete depends on aggregate size, the mesh size needed to be greater than the maximum

14 aggregate size [31] for accurate results. This slab specimen was chosen because it failed in punching

15 shear experimentally. Heating was provided in Smith's experiments by radiant panel heaters, with a

16 peak surface temperature of around $480^{\circ} \mathrm{C}$, the thermal history was recorded using thermocouples [8].

17 Based on the heating data shown in Figure 5, a thermal profile was numerically developed using the

18 heat transfer model with heat transfer elements from the Abaqus library [32], then the static loading

19 was applied. In the numerical model, this procedure was carried out in two stages. The first stage is by

20 conducting a thermal heat transfer model to generate the thermal profile for the slab. The second stage

21 was implemented by incorporation of this thermal profile into a stress model to apply static load. 


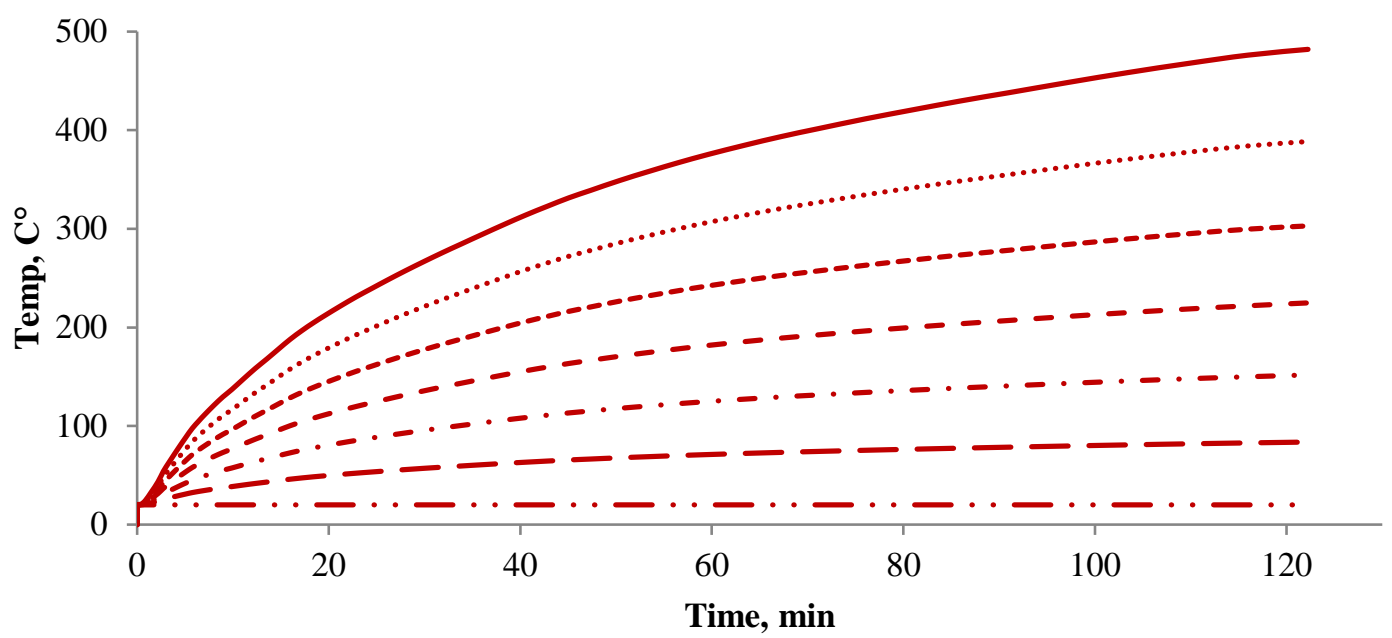
- Hot surface adopted from experiment - - - - Calculated temperature at $50 \mathrm{~mm}$ - - Calculated temperature at $25 \mathrm{~mm}$

........ Calculated temperature at $62.5 \mathrm{~mm}$

- - - Calculated temperature at $37.5 \mathrm{~mm}$

— Calculated temperature at $12.5 \mathrm{~mm}$

2 Figure 5 Temperature-time data through the depth of the slab (Adapted from [9] under Creative Commons License).

3 As explained in section 3, an additional strain component was introduced to the EC2 concrete model so

4 that the effect of LITS could be captured numerically as shown in Figure 4.

5 In the current EC2 (EN 1992-1-2:2004) [11], some modification was made to the material behaviour,

6 with the intention of including the additional strain component (LITS) implicitly [14]. The numerical

7 model showed that the current EC2 model includes for the LITS effect in part but not fully. However,

8 the model proposed by Al-Hamd et al. $[9,10,30]$ is shown to capture the observed unexpected behaviour

9 in the experiment, see figure 6. In the Al-Hamd model, the addition of the LITS component is made

10 explicitly in line with research performed by Lange and Jansson $[14,15]$ highlighting the poor inception

11 of LITS in the current EC2. 


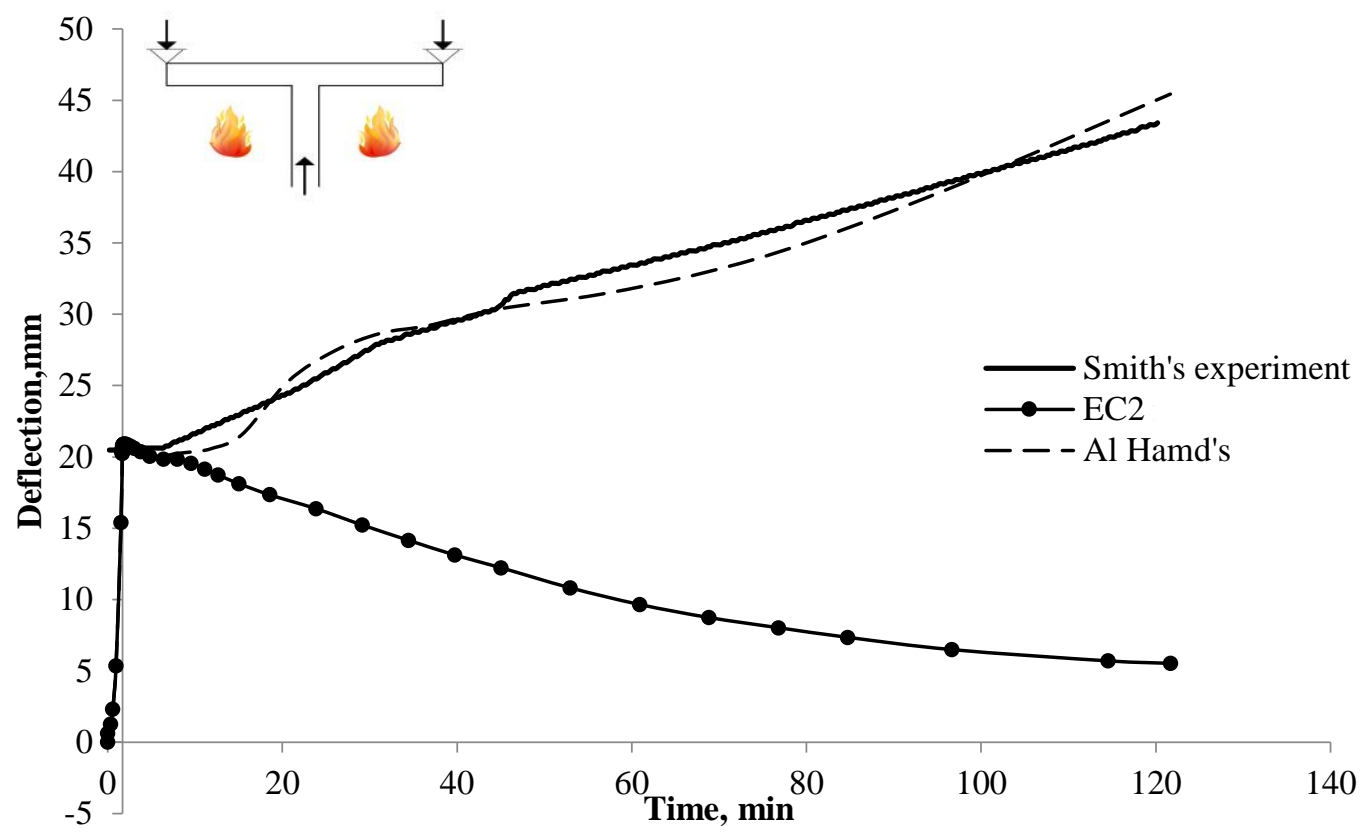

2 Figure 6 Deflection-time response of Smith's slab, together with numerical predictions for the EC2 model (with LITS being incorporated implicitly) and Al-Hamd's model (with LITS)

4 In order to ensure the appropriateness of the mesh size, a sensitivity study was carried out with three

5 different mesh sizes: a fine $(10 \mathrm{~mm})$, medium $(12.5 \mathrm{~mm})$ and coarse $(15 \mathrm{~mm})$ mesh. The sensitivity

6 study shown in Figure 7 suggests that the slab with the medium size mesh $(12.5 \mathrm{~mm})$ is the best fit to

7 the experimental results and more computationally efficient than the fine mesh; therefore, this mesh

8 size would be adopted in all of the following analysis. 


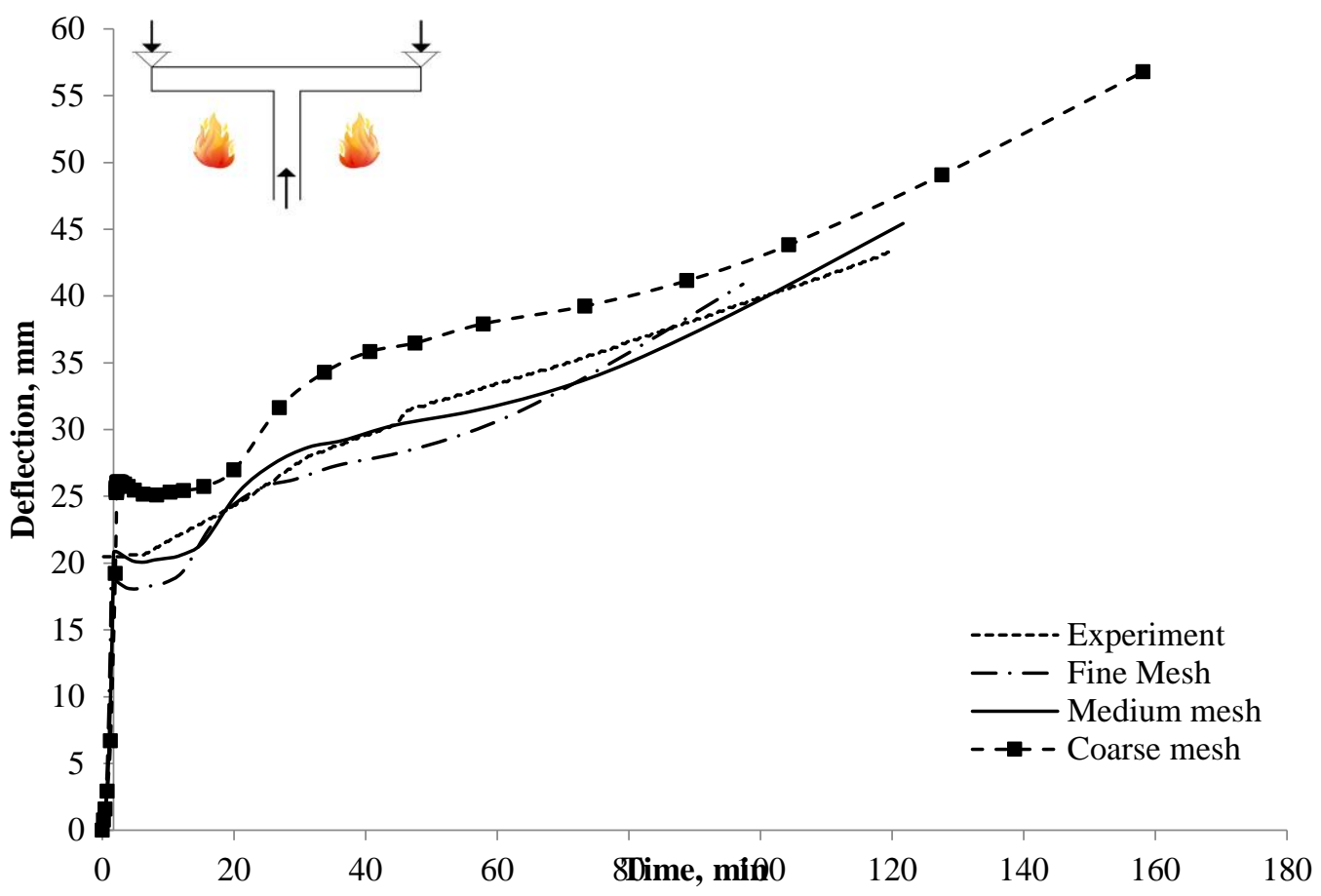

2 Figure 7 Mesh sensitivity study showing the deflection-time response for different mesh sizes against experimental results

\section{6. Effect of continuous heating}

5 This section examines the effect of a continuous heating scenario on the deflection response and the

6 failure mode of the slab examined in Section 5. In this scenario, the initial heating regime measured by

7 Smith was included and was then extended by assuming a linear increase in temperature after the

8 experimental measurements were stopped. Figure 8 shows the predicted deflection behaviour plotted

9 against time. The rapid increase in the deflection can qualitatively pinpoint the failure of the RC slab

10 for both cases. However, the failure occurred earlier when the LITS component was included in the

11 model. The model adopted by the current EC2 (that assumes the implicit inclusion of LITS) seems to

12 over-predict the failure time (temperature) in comparison to the Al-Hamd model. The Al-Hamd model

13 failed when the top surface temperature reached $710^{\circ} \mathrm{C}$ while the $\mathrm{EC} 2$ model resisted the fire loading

14 up to about $870^{\circ} \mathrm{C}$. Also, these models demonstrate a large difference in the deflection response due to

15 the effect of the LITS component [15]. If we say that slab failure occurs when deflection reaches span 
1 length/20 (=50 $\mathrm{mm}$ in this case) ( based on the deflection limits for a reinforced concrete beam/slab

2 according to BS 476-23:1987 [33]), overlooking the effect of LITS can increase the exposed surface

3 predicted failure temperature by about $100^{\circ} \mathrm{C}$. This difference might result in non-conservative design

4 recommendations.

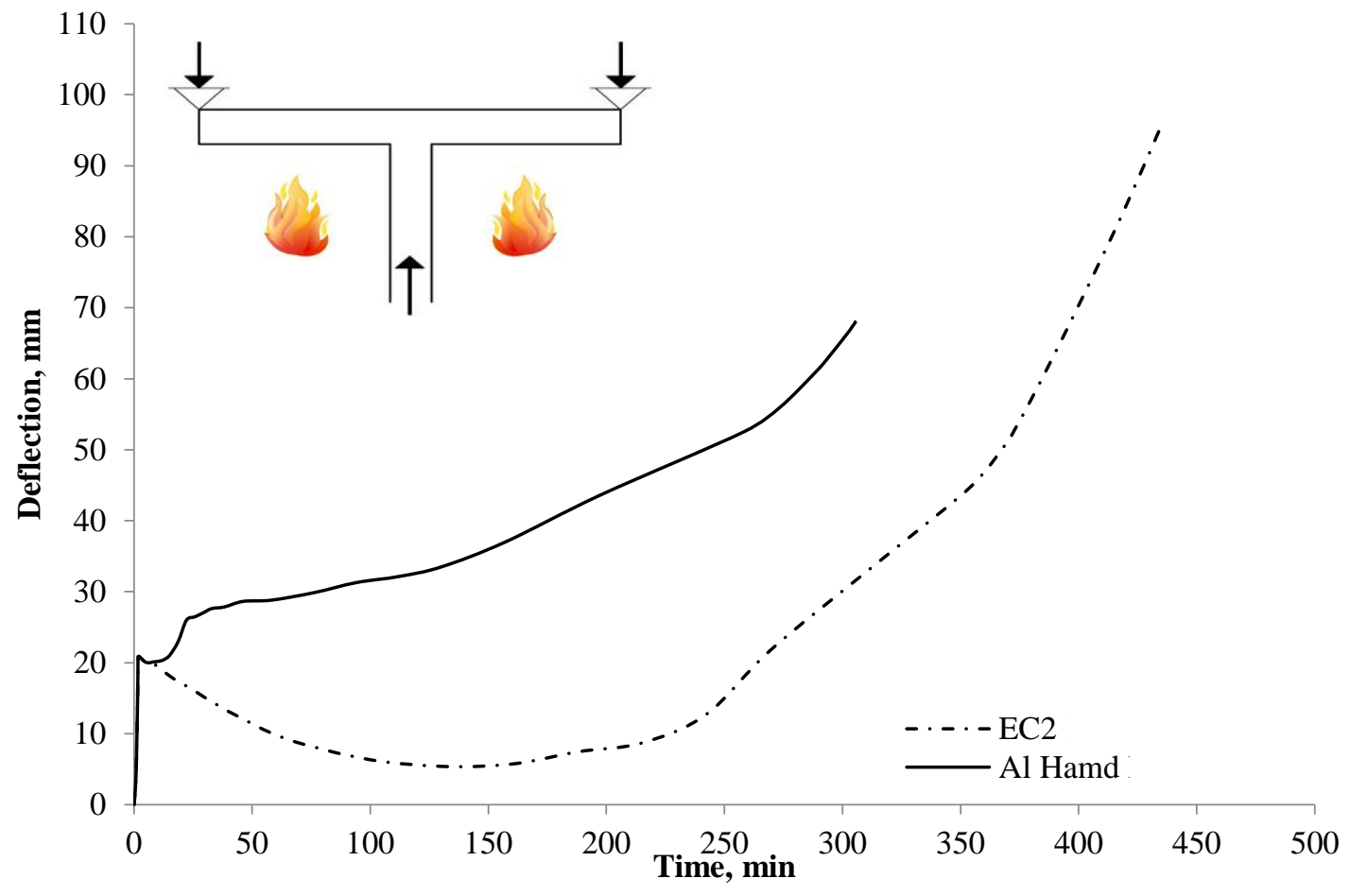

Figure 8 Deflection response against time the continues heating scenario

\section{7. Effect of different loading ratios}

8 As stated earlier, the level of in-service loading in relation to structural capacity can affect directly the

9 structural behaviour for a concrete building in fire as a result of the different strain components

10 generated. In this section, this effect is investigated on a material level first, and its implication on

11 structural behaviour is also discussed. 


\section{$1 \quad 7.1 \quad$ Material level (Simplified case)}

2 To build a thorough understanding on the effect of the strain components in the adopted concrete

3 model in representing RC slabs, standard concrete cubes $(100 \times 100 \times 100 \mathrm{~mm})$ [34] were modelled

4 using the modelling approach previously described, see Figure 9 (the mesh size used is $12.5 \mathrm{~mm}$ see

5 Section 5). Similar heating scenarios to that in the previous section were assumed. Different loading

6 ratios were explored to capture the initiation of the LITS component. Four different LRs, namely 25\%,

$750 \%, 70 \%$ and $80 \%$ of the ultimate compressive failure load at ambient temperature, was applied to

8 the specimens with and without LITS.

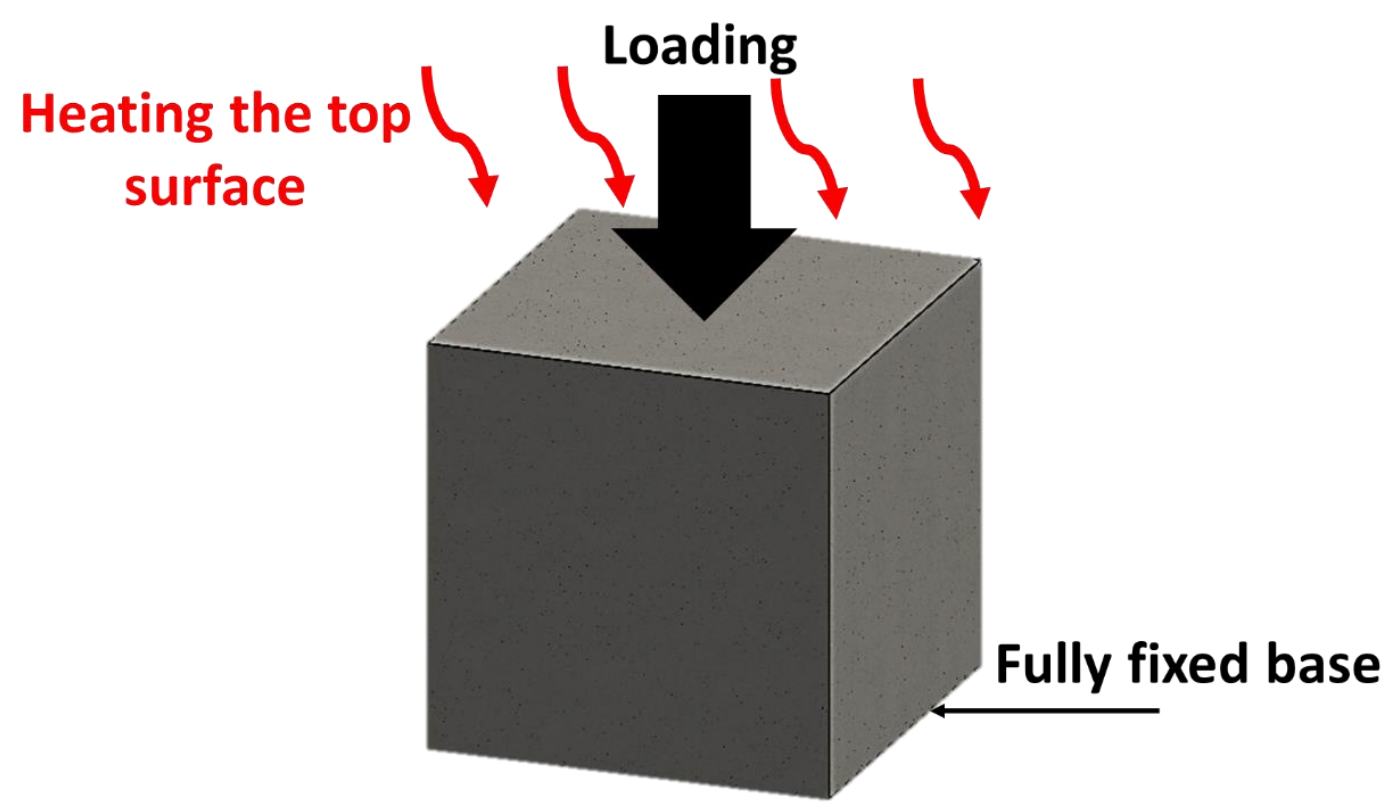

Figure 9 Conceptual diagram for the cube under the combined heating and loading scenario

11 Figure 10 shows the deflection of the concrete cube (indicating the strain) with two concrete models

12 one with LITS implicitly included (EC2) and one with LITS explicitly included (Al-Hamd). It can be

13 observed that increasing the LR magnifies the effect of the LITS component over the effect of the

14 thermal strain (thermal expansion). However, with low loading ratios (such as 20\%) the effect does

15 not contribute to reversing the deflection direction of the concrete cube since the specimen still 
1 deflects towards the heating source (i.e. (for the deflection response -ve deflection moving upwards,

2 +ve moving downwards)). On the other hand, at high LRs the effect of LITS can be substantial and

3 results in reversing the expected deflection direction of the cube. As discussed previously, this can

4 explain Kordina's [1,2] observation in the slab tests (Figure 2a and b). At the earlier stages of the

5 heating process, deflection at such lower temperature can be towards the heating source depending on

6 the test setup; this can be seen in the cube in Figure 9 LR $70 \%$.

7 There is a clear difference between the implicit and explicit addition of the LITS strain component 8 and this might result in overestimating the fire resistance of the structural member. Therefore, the 9 explicit addition of the LITS component should be considered in order to ensure a more reliable design 10 is achieved. 


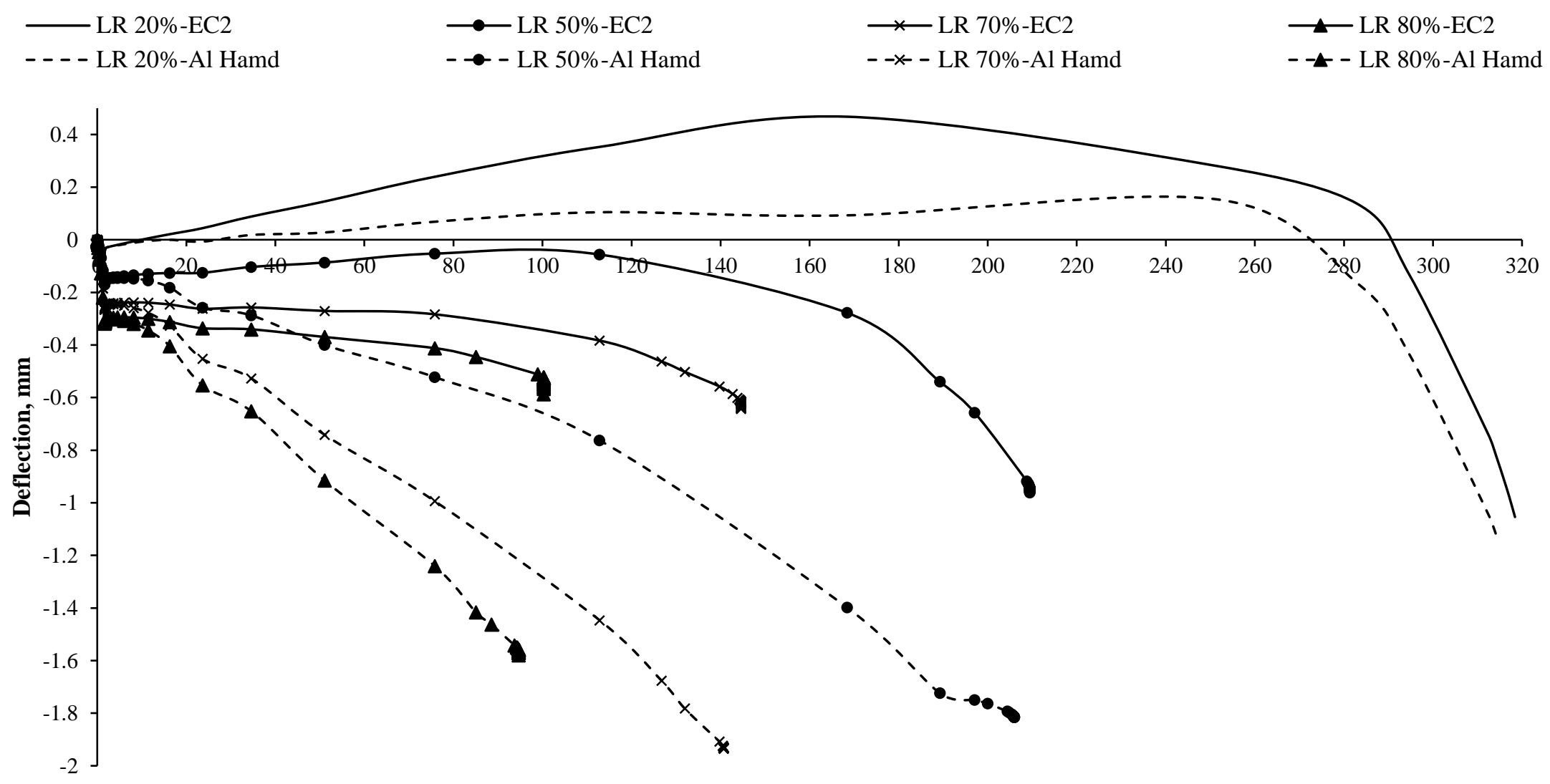

Time, min

2 Figure 10 Deflection-time response for different loading ratios at the centre of a standard cube (the solid lines represent the EC2 model and the dashed lines represent the

Al Hamd model) 


\section{$1 \quad 7.2$ Structural behaviour of the slab-column connection}

2 Here the slab discussed in section 5 is subjected to 4 different loading ratios at high temperature. Using

3 the approach adopted by Smith [8], the loading ratio is taken to be (the applied load) /(80\% of the

4 experimentally obtained punching shear capacity at ambient temperature). Load ratios of $25 \%, 50 \%$,

$570 \%$ and $80 \%$ were chosen.

6 From figure 10, it can be noted that a step change in deflection behaviour occurs when higher LRs are

7 applied triggering the load-induced thermal strain effect, this is in line with the previously described

8 work by [2] and the material level modelling (Figure 3). Figure 11 shows the maximum principal strain

9 in the section with different loading levels. From Figure 10 and 11 it can be clearly seen that the failure

10 profile was affected by the different loading ratios. The change in the loading level had a small effect

11 on the slab heat resistance as the specimen with a lower loading ratio $(25 \%)$ had more heat resistance,

12 collapsing after $378 \mathrm{~min}\left(890^{\circ} \mathrm{C}\right)$ of heating, followed by the specimen with a $50 \%$ loading ratio, which

13 collapsed after $352 \mathrm{~min}\left(775^{\circ} \mathrm{C}\right)$, the specimen with $70 \%$ loading ratio, which collapsed after $330 \mathrm{~min}$

$14\left(744^{\circ} \mathrm{C}\right)$ and, finally, the specimen with $80 \%$ loading ratio, which collapsed after $304 \min \left(710^{\circ} \mathrm{C}\right)$, this

15 would seem to follow the intuitive pattern of results. 


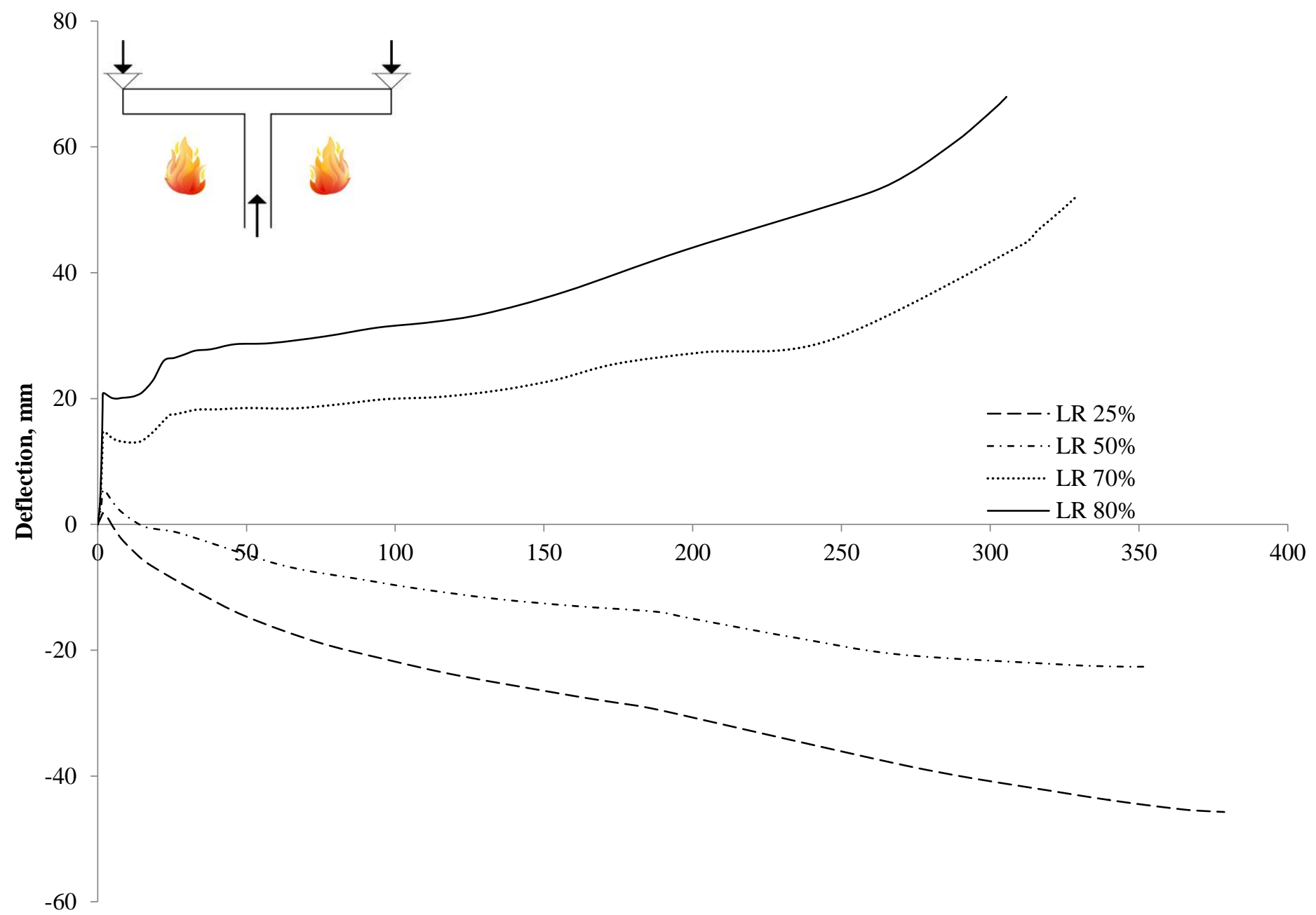

Time, $\min$

Figure 11 Deflection-time response for different loading ratios at the centre of the slab 
1 According to the concrete damage plasticity theory used in the model, when the plastic strain exceeds

2 zero a crack will develop. The maximum principal plastic strains shown in Figure 11 can be used to 3 indicate the cracking pattern in the slab at the end of heating, where the characteristic cone shape of 4 failure by punching shear is noticeable. However, the influence of different loading ratios changes the 5 deflection profile due to the effect of thermal expansion and LITS. The cone-shaped failure profile of

6 punching shear is still noticeable in all of the cases, numerically demonstrating that all models failed 7 with the same failure mechanism. 


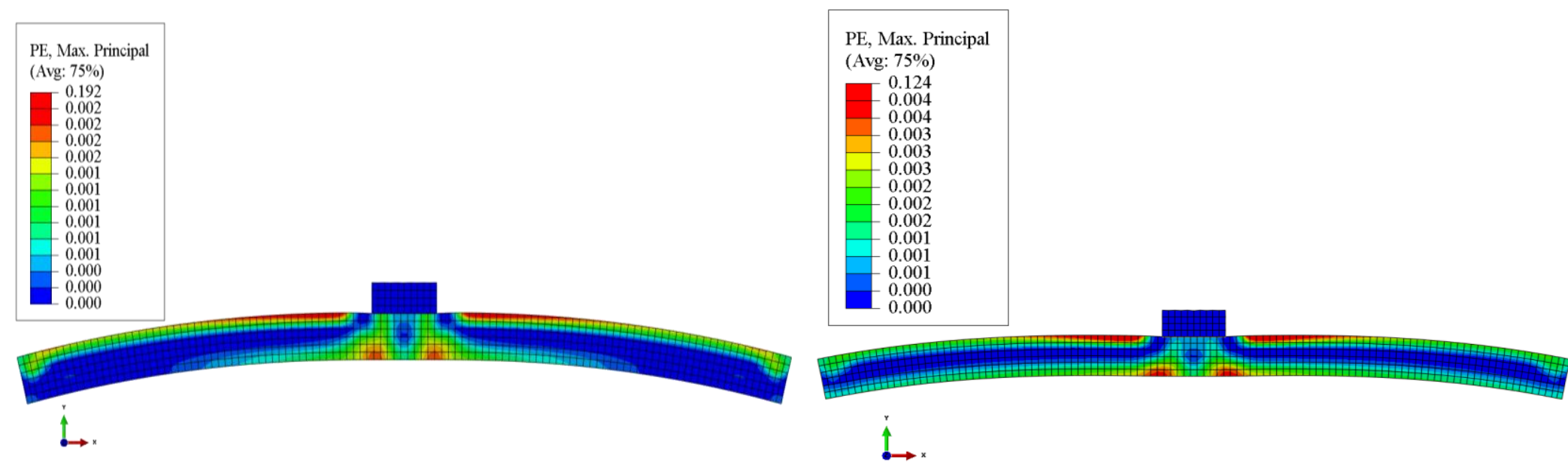

(a)

(b)
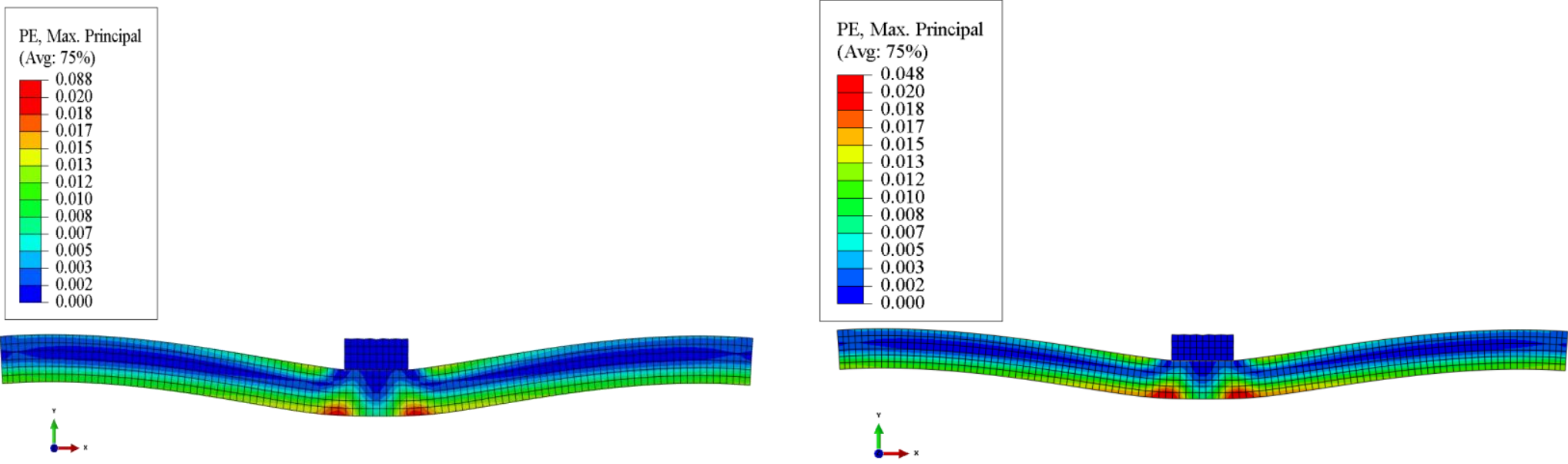

(c)

(d)

Figure 12 Cracking pattern at the stage of anticipated failure for slab S75 with loading ratio (a) LR 25\%, (b) LR 50\%, (c) LR 70\% and (d) LR $80 \%$ 
1 The proposed failure profile, along with the failure envelope for the slab with different loading

2 ratios, is shown in Figure 12 where the assumed crack had travelled across half of the slab. The

3 failure envelope shows the maximum tensile stress that the concrete can sustain at each location,

4 taking into account the temperature-profiles and how the concrete material properties vary with

5 temperature. The failure profile shows the maximum principal stresses through the thickness of

6 the slab for the continuous-heating scenario (measured from bottom to top along with a crack

7 path at $45^{\circ}$ degrees to the horizontal plane from the column face). Figure 12 demonstrates that

8 the different behaviour observed for each LR did not affect the failure mechanism for the slabs.

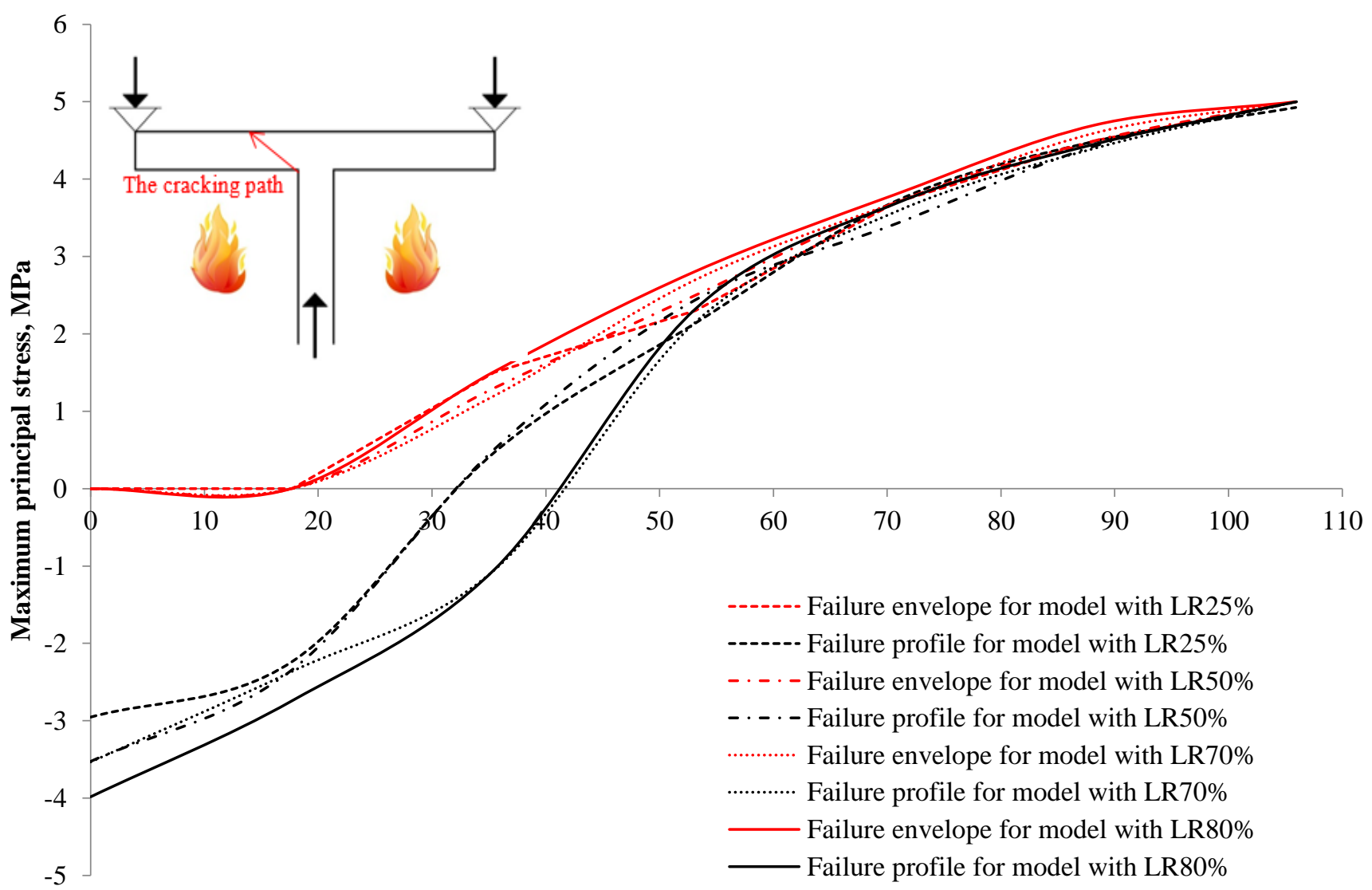

Distance along crack path, mm

9

10

Figure 13 Failure envelopes along with the failure profiles for different loading ratios 


\section{8. Conclusions}

2 This paper has explored via numerical modelling the effects of explicitly including load-induced

3 thermal strain on the behaviour of concrete at both material and structural levels. The effect of

4 modifying the concrete model can substantially affect the structural behaviour and improve

5 response prediction. The implemented model is able to capture the unexpected experimental

6 behaviour reported in the literature and offers some rationale for the observed phenomenon.

7 It has been demonstrated that the choice of LITS model has a significant impact on structural

8 behaviour at elevated temperatures. For the particular slab scenario examined, the Al Hamd

9 LITS model is able to capture the experimentally observed behaviour while markedly less

10 accurate results were predicted by the implicit LITS model from Eurocode 2

11 Exploring different loading ratios showed that this parameter can dramatically change the

12 deflection response for the same slab, yet this did not majorly affect the slab load resistance. The

13 change in the loading ratio especially when the loading ratio is more than $50 \%$ of the ultimate

14 tested capacity of the concrete slab at ambient temperature, directly affects the deflection

15 behaviour of the member at both material and structural levels. An understanding of the

16 structural system response at different load levels, accounting for the effects of LITS, is key to

17 developing strategies for safety in fire situations. The work presented here has concentrated on

18 one particular slab geometry and at a relatively small scale. Further work is required both

19 numerically and experimentally to understand the effects of LITS and loading ratio in full-scale

20 building scenarios. 


\section{9. References}

2 [1] Kordina K. Über das Brandverhalten punktgestützter Stahlbetonplatten. Braunschweig, 3 Oktober: 1993.

4 [2] Kordina K. Über das Brandverhalten punktgestützter Stahlbetonplatten (On the Fire

11 [5] Smith HKM, Stratford T, Bisby L. Deflection Response of Reinforced Concrete Slabs

[7] Smith HKM, Stratford T, Bisby L. The Punching Shear Mechanism in ReinforcedTested in Punching Shear in Fire. Appl. Struct. Fire Eng., Dubrovnik, Croatia: 2015.

[6] Smith HKM, Stratford TJ, Bisby LA. Punching Shear of Reinforced Concrete Slabs under Fire Conditions: Experiment vs. Design. CONFAB 2015 Conf. Proc., Glasgow , United Kingdom: ASRANet Ltd; 2015.

[8] Smith HKM. Punching Shear of Flat Reinforced-Concrete Slabs under Fire Conditions. The University of Edinburgh, 2016. 
1 [9] Al Hamd RKS, Gillie M, Warren H, Torelli G, Stratford T, Wang Y. The effect of load2 induced thermal strain on flat slab behaviour at elevated temperatures. Fire Saf $\mathbf{J}$ $3 \quad 2018 ; 97: 12-8$. doi:10.1016/j.firesaf.2018.02.004.

4 [10] Al Hamd RKS, Gillie M, Wang Y. Numerical modelling of slab-column concrete 5 connections at elevated temperatures. IABSE Symp Rep 2017;109:3365-9. 6 doi: $10.2749 / 222137817822208528$.

7 [11] EN1992-1-2-2004. Eurocode 2: Design of Concrete Structures - Part 1-2: General Rules 8 - $\quad$ Structural $\quad$ Fire Design. $\quad$ Eurocode $\quad 2,2004$. 9 doi:https://archive.org/details/en.1992.1.2.2004.

10 [12] Torelli G, Mandal P, Gillie M, Tran VX. Concrete strains under transient thermal 11 conditions: A state-of-the-art review. Eng Struct 2016;127:172-88. 12 doi:10.1016/j.engstruct.2016.08.021.

13 [13] Andrew H. Buchanan C. Structural Design for Fire Safety. University of Canterbury, 14 New Zealand: John Wiley \& Sons; 2002. doi:doi:10.1201/9781420039931.ch37.

15 [14] Lange D, Jansson R. A comparison of an explicit and an implicit transient strain 16 formulation for concrete in fire. Fire Saf Sci 2014;11:572-83. 17 doi:10.3801/IAFSS.FSS.11-572.

18 [15] Jansson R, Lange D. The fire behaviour of an inner lining for tunnels. 2015.

19 [16] Thelandersson BS. MODELING OF COMBINED THERMAL AND MECHANICAL 20 ACTION IN CONCRETE. J Eng Mech 1987;113:893-906.

21 [17] Ring T, Zeiml M, Lackner R, Eberhardsteiner J. Experimental investigation of strain 
1 behaviour of heated cement paste and concrete. Strain 2013;49:249-56. 2 doi:10.1111/str.12032.

3 [18] Ring T, Zeiml M, Lackner R. Underground concrete frame structures subjected to fire 4 loading: Part II - Re-analysis of large-scale fire tests. Eng Struct 2012;58:188-96. $5 \quad$ doi:10.1016/j.engstruct.2012.10.021.

6 [19] Zhang Y, Zeiml M, Pichler C, Lackner R. Model-based risk assessment of concrete $7 \quad$ spalling in tunnel linings under fire loading. Eng Struct 2014;77:207-15. doi:10.1016/j.engstruct.2014.02.033.

9 [20] Zhang Y, Zeiml M, Maier M, Yuan Y, Lackner R. Fast assessing spalling risk of tunnel 10 linings under RABT fire: From a coupled thermo-hydro-chemo-mechanical model 11 towards an estimation method. Eng Struct 2017;142:1-19. 12 doi:10.1016/j.engstruct.2017.03.068.

13 [21] Anderberg Y, Thelandersson S. Stress and deformation characteristics of concrete at high temperature: 2. Experimental investigation and material behaviour model. Bull No

16 [22] Law A. The Assessment and Response of Concrete Structures Subjected to Fire. The $17 \quad$ University of Edinburgh, 2010.

18 [23] Rabczuk T, Belytschko T. Cracking particles: A simplified meshfree method for 19 arbitrary evolving cracks. Int J Numer Methods Eng 2004;61:2316-43. doi:10.1002/nme.1151.

21 [24] Rabczuk T, Zi G, Bordas S, Nguyen-Xuan H. A geometrically non-linear three- 
1 dimensional cohesive crack method for reinforced concrete structures. vol. 75. 2008.

2 doi:10.1016/j.engfracmech.2008.06.019.

3 [25] Rabczuk T, Zi G, Bordas S, Nguyen-Xuan H. A simple and robust three-dimensional 4 cracking-particle method without enrichment. Comput Methods Appl Mech Eng 2010;199:2437-55. doi:10.1016/j.cma.2010.03.031.

6 [26] Rabczuk T, Belytschko T. A three-dimensional large deformation meshfree method for

11 [28] Abdulrahman BQ, Wu Z, Cunningham LS. Experimental and numerical investigation arbitrary evolving cracks. Comput Methods Appl Mech Eng 2007;196:2777-99. doi:10.1016/j.cma.2006.06.020.

[27] Areias P, Rabczuk T, Camanho PP. Initially rigid cohesive laws and fracture based on edge rotations. Comput Mech 2013;52:931-47. doi:10.1007/s00466-013-0855-6. into strengthening flat slabs at corner columns with externally bonded CFRP. Constr Build Mater 2017;139:132-47. doi:10.1016/j.conbuildmat.2017.02.056.

[29] Genikomsou AS, Polak MA. Finite Element Analysis of Punching Shear of Concrete Slabs Using Damaged Plasticity Model in ABAQUS. Eng Struct 2015;98:38-48.

[30] Al-Hamd RKS, Gillie M, Cunningham LS, Warren H, Albostami AS. Novel shearhead reinforcement for slab-column connections subject to eccentric load and fire. Arch Civ Mech Eng 2019;19:503-24. doi:10.1016/j.acme.2018.12.011.

[31] CEB-FIP. Model Code Design of Concrete Structures MC90. London: Thomas Telford Ltd.; 1990.

[32] ABAQUS, User's Manual, Version 6.13. Dassault Systémes Simulia Corp, Provid 
Rhode 2013.

2 [33] BS 476-23:1987. Fire tests on building materials and structures — British Standards $3 \quad$ Institution, London, UK. 1987.

4 [34] CEB-FIP International Federation for Structural Concrete (fib). Structural Concrete:

5 Textbook on Behaviour, Design and Performance: Updated Knowledge of the CEB/FIP

6 Model Code 1990. vol. bulletin 5. Lausanne, Switzerland: 2009. doi:10.1017/CBO9781107415324.004. 